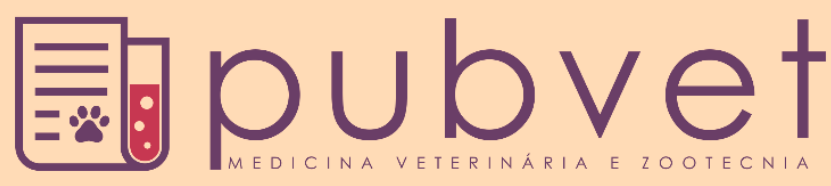

https://doi.org/10.31533/pubvet.v13n11a457.1-7

\title{
Dermatite atópica em uma cadela: caso clínico
}

\author{
Walterez Geralda de Araujo Barboza ${ }^{1 *}$, Elaine Waite de Souza ${ }^{2} \bullet$, Andrea Moreira Paulino ${ }^{3} \bullet$ \\ ${ }^{1}$ Médica Veterinária Aluna do Curso de Pós graduação em Clinica e Cirurgia de Cães e Gatos da Faculdade Qualittas. Rio de Janeiro. Brasil. \\ ${ }^{2}$ Médica Veterinária Doutora em Clínica e Cirurgia responsável pela Toca do Bicho. Rio de Janeiro. Brasil. \\ ${ }^{3}$ Médica Veterinária Professora da Faculdade de Medicina Veterinária Estácio de Sá. Rio de Janeiro. Brasil. \\ *Autor para correspondência, E-mail: bwalterez@hotmail.com,waiteelaine46@gmail.com
}

Resumo. A dermatite atópica é causada habitualmente por três tipos de alérgenos: os pólens, os ácaros e os fungos. São subdivisões das dermatoses alérgicas a dermatite alérgica à picada de pulgas, a alergia alimentar e a dermatite atópica. O diagnóstico das dermatoses alérgicas é clínico e sempre feito por exclusão. Em cães usa-se os critérios de Favrot. Os exames laboratoriais existentes são apenas complementares, assim como os testes intradérmicos ou sorológicos. Tricogramas auxiliam ao determinar se a alopecia é causada por autotraumatismo e, nesses casos, observa-se o pelo tonsurado (quebrado). A citologia deve ser executada no animal com prurido com exceção dos que apresentam alopecia não inflamatória. Podemos colher material pelo raspado cutâneo ou pela fita adesiva. O tratamento das dermatoses alérgicas deve ser com terapia antiprurido, combater ectoparasitos, combater as afecções oportunistas, hidratação, ômega 3, podendo ainda utilizar imunimoduladores, imunoterapia, luz ultravioleta, autohemoterapia e psicotrópicos.

Palavras chave: citologia, prurido, Favrot, tricograma

\section{Atopic dermatitis in a bitch: clinical case}

Abstract. Atopic dermatitis is usually caused by three types of allergens: pollen, mites and fungi. Subdivisions of allergic dermatoses are allergic to flea bite dermatitis, food allergy and atopic dermatitis. The diagnosis of Allergic Dermatoses is clinical and always done by exclusion. In dogs, Favrot's criteria are used. Existing laboratory tests are only complementary, as are intradermal or serological tests. Tricograms Aids in determining if alopecia is caused by self-injury and, in these cases, the tonsured (fractured) hair is observed. Cytology Should be performed on every animal with pruritus except for those with non-inflammatory alopecia. We can collect material by skin scraping or by the adhesive tape. The treatment of Allergic Dermatoses should be with antipruritic therapy, combat ectoparazites, combat opportunistic diseases, hydration, omega 3 , and may also use immunimodulators, immunotherapy, ultraviolet light, autohemotherapy, and psychotropic.

Keywords: cytology, Favrot, pruritic, trichrome

\section{Dermatitis atópica en una hembra canina: caso clínico}

Resumen. La dermatitis atópica generalmente es causada por tres tipos de alérgenos: polen, ácaros y hongos. Las subdivisiones de las dermatosis alérgicas incluyen dermatitis alérgica por pulgas, alergia alimentaria y dermatitis atópica. El diagnóstico de dermatosis alérgicas es clínico y siempre se realiza por exclusión. En los perros se utilizan los criterios de Favrot. Las pruebas de laboratorio existentes son solo complementarias, al igual que las pruebas intradérmicas o serológicas. Los tricogramas ayudan a determinar si la alopecia es causada por autotraumatismo $\mathrm{y}$, en esos casos, se observa el pelo amurallado (quebrado). La 
citología debe realizarse en el animal con prurito, excepto en aquellos con alopecia no inflamatoria. Podemos colectar material raspando cutáneo o con cinta adhesiva. El tratamiento de la dermatosis alérgica debe ser con terapia anti-prurito, prevenir y tratar ectoparásitos, combatir trastornos oportunistas, hidratación, suplementación con omega 3, y también puede usar inmunomoduladores, inmunoterapia, luz ultravioleta, autohemoterapia y psicotrópicos.

Palabras clave: Citología, prurito, Favrot, tricograma

\section{Introdução}

Alergias são divididas em três grupos: Dermatite alérgica a picada de pulgas, dermatite atópica e dermatite trofoalérgica (Solomon et al., 2012). O diagnóstico da atopia é obtido após descartar as outras dermatopatias pruriginosas, como hipersensibilidade alimentar, alergia a picada de pulgas (DAPP), dermatofitose, ectoparasitose (Cheiletielose), sarna otodecica (Otodectescynnotis), escabiose felina (Notoedriscati), demodicose felina, alopecia psicogênica, piodermites, neoplasias, paraneoplasias, dermatite alérgica por contato e malasseziose. Na dermatite alérgica a picada de pulgas, observa-se um padrão miliar, podendo estar presente na atopia também. Na dermatite trofoalérgica a manifestação clínica mais comum em cães é o prurido severo de carácter não-sazonal, principalmente nas patas dos membros torácicos com hiperemia. O dorso e orelhas apresentam-se normais. A otite está presente em muitos casos, mesmo que o proprietário não tenha percebido. Os principais alérgenos alimentares são produtos lácteos (leite, queijo), peixe, carne, frango e ovos. As dermatites trofoalérgicas são mais comuns em gatos do que em cães, e o alérgeno envolvido é normalmente uma proteína, pois estas conseguem unir duas moléculas de IgE aos mastócitos, provocando a sua degranulação e liberação de mediadores inflamatórios (Tizard, 2014). As dietas testem incluem uma nova proteína hidrolisada que pode ser uma dieta comercial com proteína hidrolisada de cordeiro, coelho porco ou cavalo ou uma dieta caseira por 8 a 12 semanas. Após esse período, é reintroduzida a dieta original e observar se haverá exacerbação dos sintomas. As rações de baixa qualidade possuem muitos alérgenos como partes de insetos e proteínas de baixo aproveitamento. Deve-se sempre orientar o proprietário a mudar a ração para super-premium.

Algumas raças são geneticamente mais predispostas do que outras a desenvolver reações alérgicas, como Boxer, Dálmata, Chow-chow, Labrador e Golden Retriever, Setter, Pastor Alemão, Sharpei, Bulldog (inglês e francês), Terriers (West Highland White Terrier, Yorkshire Terrier). O sintoma principal é o prurido e alopecia autoinduzida, bilateral e simétrica. O proprietário pode perceber que existe prurido devido ao vômito dos tricobezoares, pelos nas fezes, tufos de pelos no chão. Nos tricogramas visualiza-se pelos tonsurados ou pela coceira, mordidas e lambeduras muitas vezes intenso. As áreas auto traumatizadas podem ser localizadas ou generalizadas.

Alguns cuidados simples devem ser adotados no ambiente para reduzir a exposição aos alérgenos; usando filtros de ar e filtros especiais, ventilação adequada, aeração de edredom, cobertor, colchão, tratar áreas com inseticidas e hormônios reguladores do crescimento de insetos, limpeza das áreas de descanso. Além disso, evitar tinta de jornal, fumaça de cigarro, penas de aves, não lavar o chão onde o animal se deita com sabão em pó, cloro concentrado, desinfetantes. Usar um copo de água sanitário para 3 litros de água. Manter o animal mais tempo fora de casa, ou, se possível, fora dos quartos e fora dos moveis de tecidos. Evitar brinquedos de tecido e grande número de plantas dentro de casa. A dermatite atópica ocorre por reação a alérgenos específicos do meio ambiente. Porém, ambiente muito limpo e com cuidados médicos maiores para o filhote influencia na maior ocorrência de dermatite atópica. Segundo Solomon et al, 2012 a exposição aos microrganismos aumenta um estímulo a Th1 ou não alérgico ao sistema imune. Dessa forma uma nova visão do exterior e a epiderme defende que uma alteração da epiderme por estímulos do exterior determina alterações genéticas com resposta imune e cascata inflamatória alteradas. Portanto o diagnóstico e tratamento são muito mais complexos do que se costumava a pensar.

A Dermatite atópica está associada à produção de IgE a alérgenos ambientais causando aumento da perda de água transepidérmica, xerose e quebra da função de barreira tegumentar facilitando o contato dos alérgenos ambientais. Os queratinócitos de cães atópicos mesmo assintomáticos têm maior aderência e colonização por Staphylococcus pseudintermedius. É comum a generalização da infecção 
por Malassézia pachydermatis. Esse patógeno exerce um papel oportunista na dermatite atópica complicada por piodermite secundária.

\section{Metodologia}

Estratégia clínica de exclusão para diagnóstico das causas da dermatite atópica no cão:

A abordagem diagnóstica à alopécia e aplicação dos critérios de FAVROT é feita na primeira consulta.

São critérios de FAVROT, o início da dermatite por volta dos três anos de idade, o cão frequentemente fica dentro de casa, o prurido responde a corticosteroide, possui otite crônica recorrente, afeta patas torácicas, afeta pina das orelhas, não afeta margens das orelhas, não afeta região dorso lombar.

Se pelo menos cinco das oito perguntas forem positivas o animal tem dermatite atópica. Se FAVROT negativo e pele com aspecto não lesional, seborreica, escamosa, brilhante, faz-se biópsia cutânea para diagnóstico diferencial de defluxo telogéneo; alopecia areata; pseudopelada; hipotricose congénita; linfoma cutâneo epitélio trófico das células. Se o teste de FAVROT for negativo e pele com aspecto de hiperfragilidade com sinais sistêmicos - faz-se perfil hematológico e bioquímico e testes hormonais, biópsias cutâneas e diagnóstico imaginológico para diagnóstico diferencial de síndrome de Cushing; hipertiroidismo ou síndrome de hiperfragilidade cutânea adquirida.

Se o teste de FAVROT for positivo aplicam-se as estratégias de exclusão para diagnóstico das causas da dermatite atópica no cão, como o controle de infecção oportunista, a hidratação das áreas atópicas, o controle das picadas de pulgas e a terapia antiprurido. Remarcar a segunda consulta em 5 semanas.

Na segunda consulta confere se seguiu prescrição e repete os exames de triagem da pele. Se a melhora foi total, o diagnóstico deverá ser dermatite alérgica a picada de pulga ou alergia alimentar. Orientar o tutor a manter hidratação e controle de pulgas a vida toda.

Na terceira consulta, reavaliar em 4 meses se a melhora foi parcial. Neste caso, triar alergia alimentar e manter hidratação e controle de pulgas. Desafiar com o alimento.

Na quarta consulta em aproximadamente em dois meses verificar se melhora foi parcial, investigando se o tutor seguiu o protocolo corretamente.

\section{Dieta de exclusão para triar a dermatite alérgica a alimentos}

Manter controle de pulgas e hidratação durante a dieta para evitar interferência no diagnóstico. Se hidratou, controlou pulga e não melhorou, faz-se a exclusão da proteína normalmente presente na ração usada pelo animal. A dieta comercial hipoalergênica para cães é balanceada, de fácil administração, muito calórica, mas a hidrólise pode não ser suficiente e ainda conter gordura de frango, vísceras de frango, soja, milho e trigo. Oferecer, em substituição à dieta habitual, exclusivamente, uma das dietas hipoalergênicas abaixo durante 8 semanas. Deve-se misturar a dieta nova com a habitual nos 5 primeiros dias.

1) Dieta comercial: ração hipoalergênica

2) Dieta caseira: Escolher um dos alimentos de cada grupo abaixo e cozinhar em partes iguais

(1kg de cada, por exemplo). Na hora de servir, adiciona-e um filete de óleo de girassol.

Grupo 1: carne de cação, coelho, pato, cavalo, rã.

Grupo 2: arroz, batata ou aipim.

Recomendações:

- Se o animal já comeu algum dos ingredientes acima, não o utilize para esta dieta. Escolha alimentos inéditos (que nunca tenha comido).

- Se precisar de algum petisco, troque as guloseimas habituais por pedacinhos de KaniKama ou da carne escolhida no grupo 1 ou por banana. 
- Durante este período, são proibidos quaisquer alimentos que não constarem desta receita, ou seja, não pode dar pão, laticínios, frutas, legumes, outras rações ou biscoitos de qualquer tipo. Se acontecer ingestão acidental de algum desses proibidos, contar mais 8 semanas a partir desse dia.

O desafio alimentar após dieta de exclusão de alergia alimentar é feito mantendo-se a dieta hipoalergênica até o retorno, oferecendo apenas uma vez 1 colher das de sopa de cada um dos alimentos suspeitos, a cada 7 dias. Anota-se se houve ou não prurido e trazer na próxima consulta e se a ração piora ou melhora o animal.

As rações hipoalergênicas disponíveis em pet shops podem conter proteína de soja hidrolisada, gordura de frango, gordura suína, gordura ovina, óleo de peixe, óleo de soja, arroz, cevada, batata, amido de milho, farinha de salmão ou hidrolisado de fígado de frango.

\section{Preparo de material na consulta}

\section{Coleta de material com fita adesiva para citologia}

Com a parte adesiva voltada para o pelo faz-se um beliscão na borda da lesão da pele e o material é colocado em uma lâmina de microscopia contendo duas gotas do corante 3 do panótico. Observa-se em aumento de 40 vezes e depois, com óleo de imersão sobre a fita adesiva no aumento de 100 vezes. É possível identificar e quantificar microrganismos, células inflamatórias e neoplásicas presentes nas lesões. No conduto auditivo usa-se cotonete seco. Na lesão nodular faz-se punção por agulha fina.

\section{Coleta de material com pinça para tricograma e cultura}

A ponta de uma pinça hemostática é protegida com um pedaço de sonda uretral para evitar quebrar o pelo. O pelo é colocado entre lâmina de microscopia para observação em microscopia óptica no aumento de 100 vezes e 400 vezes.

\section{Caso clínico}

Cadela pastor holandês de dez anos de idade com dermatite atópica desde os três anos de idade. Oito dos oito pontos dos critérios de FAVROT são positivos. A região ventral e patas apresentavam inflamação com intenso prurido devido a maior permeabilidade da pele. O dorso não apresentava lesões epiteliais macroscópicas (Figura 1).

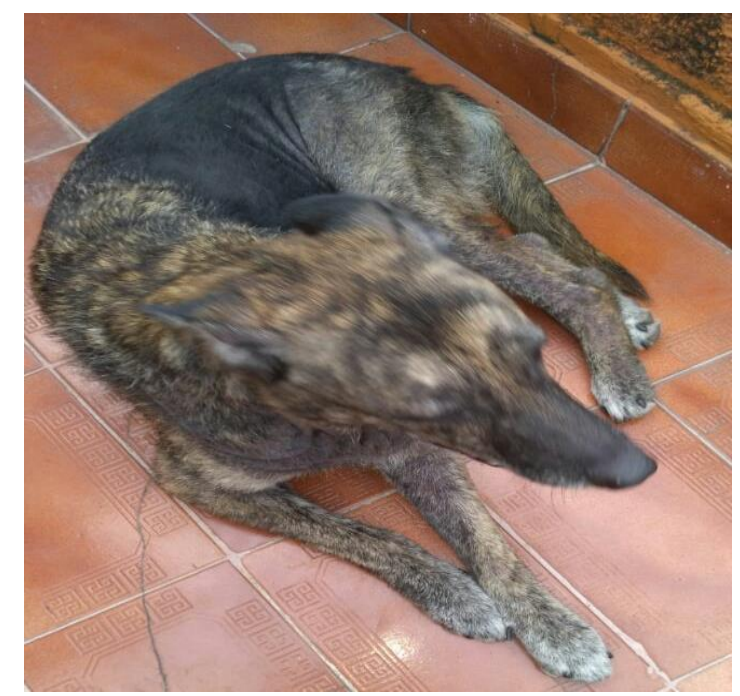

Figura 1. Cadela pastor holandês de dez anos apresenta dorso sem alterações.

\section{Terapia antiprurido}

O tratamento oral foi iniciado com a prednisolona a cada 12 horas durante 15 dias, depois se intercalou a cada 24 horas por mais sete dias e a cada 48 horas por mais sete dias. Sendo então substituído o corticosteroide por anti-histamínico hixizine a cada 12 horas durante trinta dias. Paralelamente à terapia antiprurido iniciou-se o tratamento de ectoparasitoses com sarolaner mensal. A malasseziose foi 
tratada com itraconazol por 28 dias. E as infecções bacterianas oportunistas que surgiam foram tratadas com cefalexina oral durante 21 dias.

Durante os quatro primeiros meses de tratamento foram feitos pré banhos a cada 4 dias com sabonete de peróxido de benzoíla e após enxaguar o sabonete foi dado o banho com shampoo contendo cetoconazol. Após a melhora retirou-se o pré banho com sabonete de benzoato de benzila e passou-se a usar sabonete líquido de melaleuca para o pré banho semanal. Manteve-se banho semanal com Piritionato de Zinco por mais dois meses. Após a cura total do prurido e seborreia oleosa manteve-se sabonete líquido de melaleuca para o pré banho e banho quinzenal com shampoo hipoalergênico canino, que será usado o resto da vida do animal. E após todos os banhos utilizou-se hidratante dermatológico para cães.

Suplementos que aumentam a imunidade foram utilizados contendo ácido fólico, ácido linoléico, ácido nicotínico, arginina, carnitina, selênio, glicina, lisina, colina, ferro, fósforo, cálcio, triptofano, vitaminas A, B1, B12, B2, B6, D3 e E.

\section{Resultados e discussão}

A cadela apresentava dorso sem alterações. As alterações observadas foram hiperqueratose, hipotricose, liquinificação no pescoço e toda a região ventral (Figura 2 e 3), a pina da orelha apresentava prurido (Figura 4) e observou-se otite recorrente, intenso prurido e eritema na região interna das coxas (Figura 5). A liquenificação pode ocorrer secundariamente a piodermites e a dermatite por Malassezia pachydermatis. Após 60 dias de tratamento os pelos voltaram a nascer nas áreas afetadas. A pele desinflamou, mas o espessamento só regrediu após quatro meses de tratamento. Só foram obtidos três resultados negativos em culturas fúngicas consecutivas com intervalos quinzenais após o segundo tratamento oral: itraconazol oral $10 \mathrm{mg} / \mathrm{kg}$ por 28 dias. As alterações da epiderme como liquinificação (Figura 3), foram observadas após 30 dias de contato com piso de cimento, demonstrando que o meio externo age rapidamente sobre o organismo do cão atópico alterando a barreira epidérmica fortemente.

O conjunto de critérios (Critérios de Favrot) para DAC permite estabelecer um diagnóstico clínico (Solomon et al., 2012). De acordo com Favrot (2015), cães com otite recorrente e prurido sem lesão pode ser o sintoma inicial da DAC. Os cães apresentam-se com histórico de antes dos três anos de idade terem esses sintomas, ficam dentro de casa em contato com a poeira domiciliar, lambem muito as patas da frente, respondem com melhora ao usar corticosteroides e possuem parte externa das orelhas e região dorsal da pele íntegras. Não há dados consistentes, até o momento, sobre a predisposição (Favrot et al., 2010).

Pesquisas com microscopia eletrônica demonstram alterações em lipídeos da epiderme e diminuição da retenção de água na pele (Solomon et al., 2012). As alterações epidérmicas estão associadas em todos os casos de dermatite atópica em humanos. Estudos recentes demonstraram além das alterações estruturais a diminuição de produção de peptídeos antimicrobianos e defeitos genéticos específicos por mutações genéticas da filagrina com elevada associação à dermatite alérgica (Tizard, 2014). Outros anticorpos além da $\operatorname{IgE}$ estão envolvidos na dermatite atópica, pois nem sempre foi possível provar envolvimento de IgE em 20 a $30 \%$ de pacientes humanos (De Boer, 2017). Essa nova visão precisa ser adotada na clínica de cães e gatos também, para ampliar o entendimento da alergia em animais. Segundo De Boer (2017) ocorre decréscimo da barreira epidérmica com alterações na composição do extrato córneo que resulta em aumento da permeabilidade da pele para alérgenos e agentes irritantes, e produção reduzida de peptídeos antimicrobianos pelos queratinócitos, aumentando a predisposição a infecções de pele. Esse aumento de exotoxinas microbianas na pele aumenta a resposta inflamatória acompanhada de prurido. Consequentemente surgem polimorfismos genéticos envolvendo inclusive genes codificantes de proteínas estruturais para epiderme (De Boer, 2017).

Por muito tempo pensou-se que o interior do animal era quem desencadeava a dermatite atópica, mas atualmente utilizando-se microscopia eletrônica, descobriu-se (De Boer, 2017) que uma alteração da epiderme por estímulos do exterior determina alterações genéticas com resposta imune e cascata inflamatória alteradas. Portanto o diagnóstico e tratamento são muito mais complexos do que se costumava a pensar. 


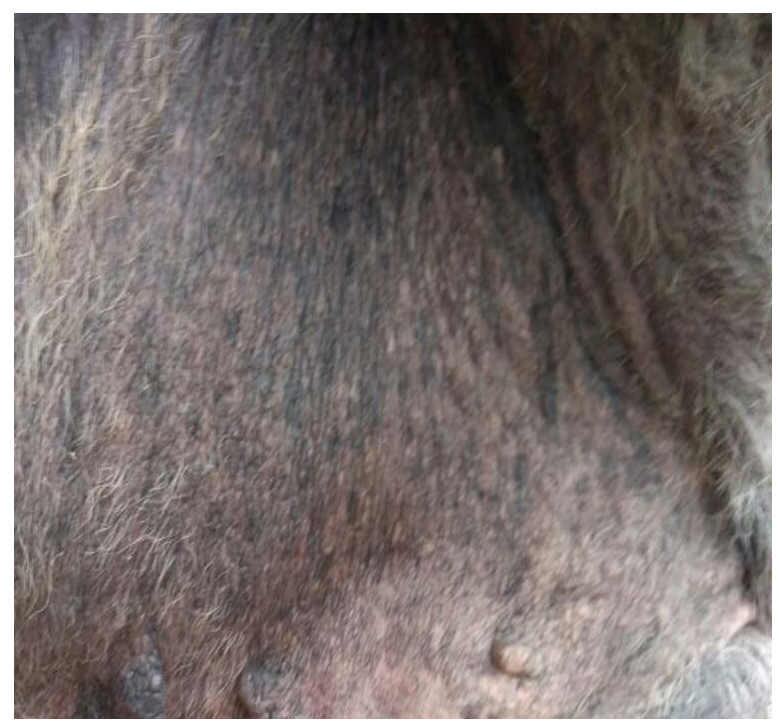

Figura 2. Infecção por Malassézia pachydermatis em cadela pastor holandês de dez anos. Pele apresenta espessamento e hiperpigmentação na região ventral.

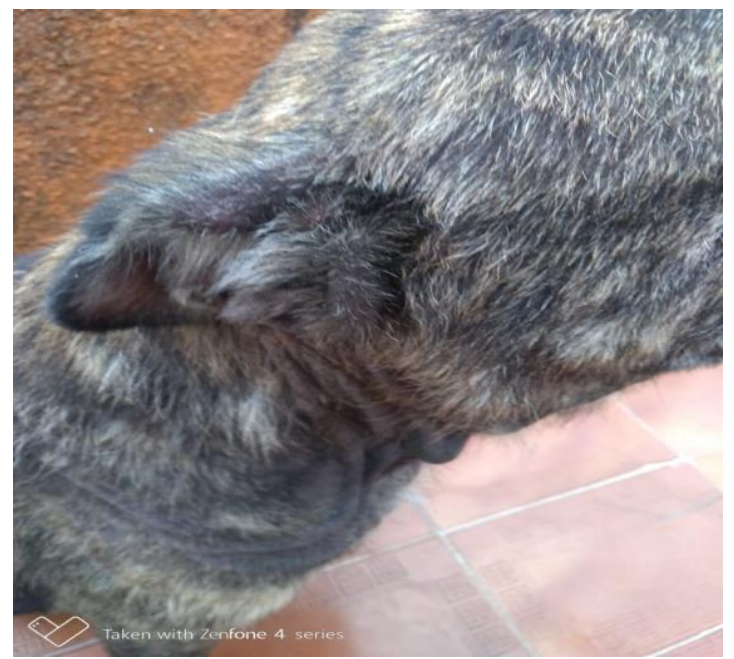

Figura 4. Pina da orelha comprometida.

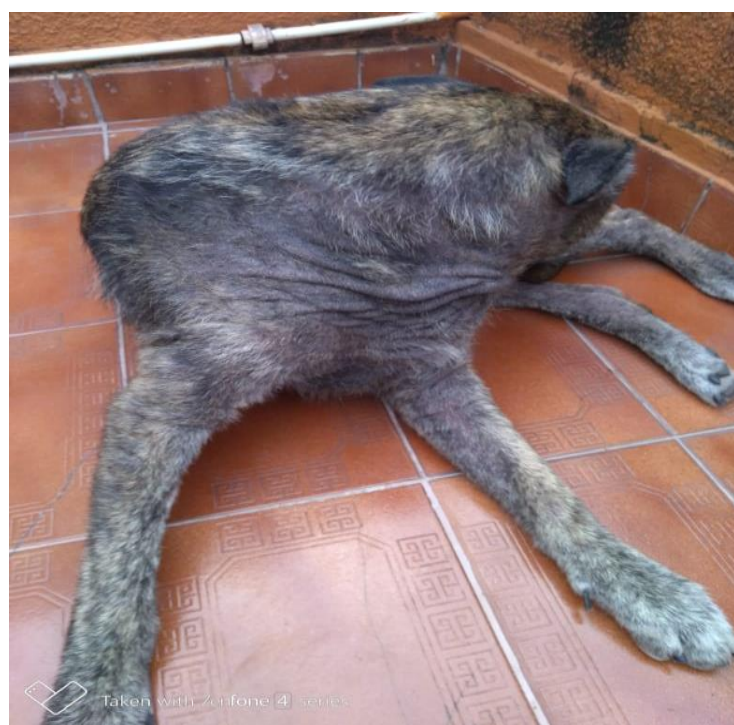

Figura 3. Alterações da epiderme em em cadela pastor holandês de dez anos com dermatite atópica, como hiperqueratose, hipotricose, liquinificação no pescoço e toda a região ventral. A liquenificação pode ocorrer secundariamente a piodermites e a dermatite por Malassezia pachydermatis.

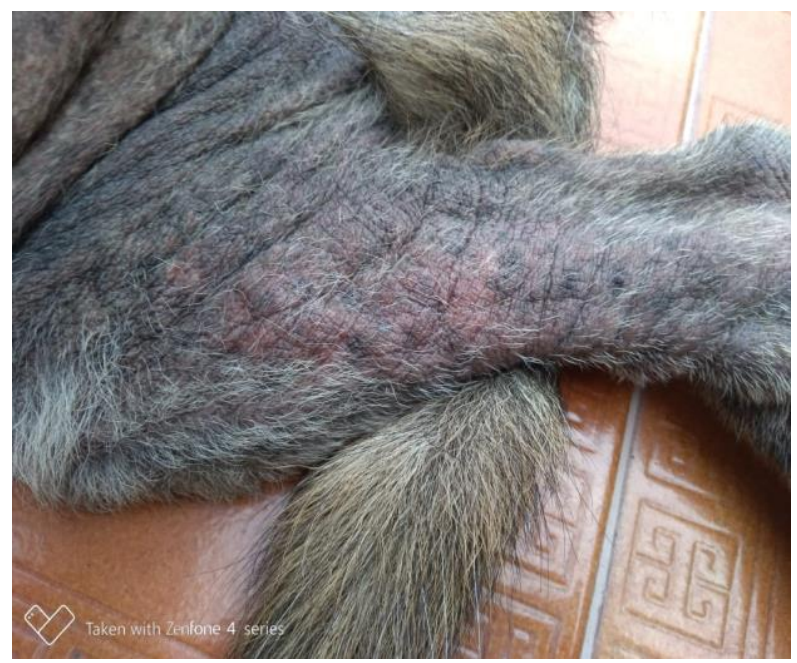

Figura 5. Intenso prurido e eritema na região interna das coxas.

A dermatite alérgica canina ainda é um desafio para os veterinários, pois sua patogenia ainda não está totalmente esclarecida. O diagnóstico é clínico por exclusão das outras dermatites. Os antihistamínicos tem eficácia baixa e muito variada, com sucesso em torno de 20 a $70 \%$. Os gatos respondem melhor do que os cães. Em cães, o maleato de oclacitinib é absorvido bem e rápidamente após administração oral combatendo eficientemente o prurido apenas. Os corticosteroides devem ser usados apenas usar para retirar o cão e o gato da crise inflamatória. Ao usar por volta de 60 dias por ano o risco de diabetes iatrogênico é alto. A auto-hemoterapia é um recurso que melhora a resposta de macrófagos na pele, podendo ser empregada em várias dermatoses. A imunoterapia com vacinas é o único tratamento que atua especificamente contra o alérgeno e que pode conduzir a uma melhora do animal com alergia. Porém há muitos debates sobre a utilidade destes testes e o melhor procedimento continua a ser a dieta caseira de exclusão alimentar quando o alérgeno tem origem no alimento.

Com a nova visão do exterior e barreira epidérmica foram descobertos novos alvos moleculares potenciais na dermatite alérgica, para os quais algumas drogas estão sendo desenvolvidas. Dessa forma, o futuro da terapia deverá incluir inibidores da Janus Kinase (JAK), antagonistas da esfignosina-1fosfato, antagonistas da neuronicina -1, antagonistas dos receptores da histamina H4. Os nervos sensoriais podem liberar neurocinas que estimulam a resposta inflamatória em um círculo vicioso de 
interação neuroimune. $\mathrm{O}$ tratamento do cão com dermatoses alérgicas é para a vida toda. $\mathrm{O}$ monitoramento da pele deve ser constante para evitar pioras desnecessárias após o contato com agentes desencadeadores de alergias.

\section{Referências bibliográficas}

De Boer, 2017. The future of Immunotherephy in canine atopic dermatitis: a revew. Veterinary Dermatology, 28: 25-e6.

Favrot, C. (2015). Clinical signs and diagnosis of canine atopic dermatitis. Zurich Open Repository and Archives Animal Breeding, 19(3):219-222.

Favrot, C., Steffan, J., Seewald, W. \& Picco, F. (2010). A prospective study on the clinical features of chronic canine atopic dermatitis and its diagnosis. Veterinary Dermatology, 21(1):23-31.

Solomon, S. E. B., Farias, M. R. \& Pimpão, C. T. (2012). Dermatite atópica canina: fisiopatologia e diagnóstico. Revista Acadêmica Ciência Animal, 10(1):21-28.

Tizard, I. R. (2014). Imunologia Veterinária: introdução. São Paulo, Brasil: Editora Roca.

Recebido: 16 de agosto, 2019.

Aprovado: 6 de outubro, 2019.

Publicado: 21 de dezembro, 2019.

Licenciamento: Este artigo é publicado na modalidade acesso aberto sob a licença Creative Commons Atribuição 4.0 (CC-BY 4.0), a qual permite uso irrestrito, distribuição, reprodução em qualquer meio, desde que o autor e a fonte sejam devidamente creditados. 